\title{
The Study of Wind Resistance Performance of Electrified Railway Catenary in Strong Wind Area
}

\author{
Neng He \\ The first department of highway design \\ Broad Vision Engineering Consultants \\ Kunming China \\ E-mail: hn881107@gmail.com
}

Jing-wei Liu

The first department of highway design

Broad Vision Engineering Consultants

Kunming China

E-mail: 183741321@qq.com

\author{
Lei Wang \\ The first department of highway design \\ Broad Vision Engineering Consultants \\ Kunming China \\ E-mail:Wl516544@163.com \\ Xue-yong Wang \\ The first department of highway design \\ Broad Vision Engineering Consultants \\ Kunming China \\ E-mail:173769100@qq.com
}

\begin{abstract}
Under the background of the catenaries of the second double line of Lan-Xin Railway in strong wind zone, we established the finite element mode of the four-span structure with catenary, and compared the value of model elastic to verify the correctness. Besides, we get some useful conclusions from the comparative study of the static and dynamic wind performance of the simple catenaries and elastic catenaries, providing the theoretical support to the catenaries design.
\end{abstract}

Keywords - catenary; wind-induced vibration; strong wind zone; finite element model

\section{INTRODUCTION}

The second double line with a full-length of $1776 \mathrm{~km}$ of Lan-Xin Railway which cross Gansu, Qinghai and Xinjiang Province goes through the Beacon Anxi wind zones in Gansu and Yandun, Baili,Sanshili and Dabancheng wind zone in Xinjiang. These wind zones are total $540 \mathrm{~km}$.

In the area of high wind, wind speed, maximum wind speed exceeds $60 \mathrm{~m} / \mathrm{s}$, the wind long, seasonal strong, steady wind, the wind blows faster, especially Barry wind zone ten miles, is one of the most powerful wind in inland areas. Gale has repeatedly caused both Portland and new southern railway overturned wheel stop. It has brought into huge economic losses and serious social impact.

As the important infrastructure electrification of the railway, The security, stability and fatigue resistance of catenaries are greatly influenced by strong winds [1]. Under the action of high wind, the catenary will move with violently vibration, affecting the pantograph high speed dynamic performance quality and shortening the life of the catenary, and even leading to the accident of pantograph-catenary. In the area with breakwind, the gale growth area appears on the breakwind and the vortex area appears after the breakwind, which can increase the movement and vibration of catenary. It will has a greater impact on the security stability and fatigue resistance of catenary, and bring bad security threat to the high-speed railway.Currently, there is little mature experience and theory in china and abroad about the result of catenary movement and vibration[2]. By theoretically analyzing, choosing the catenary with better wind resistance can provide crucial scientific evidence for the construction of the second double-track Lan-xin catenaries.

According to the case of previous studies on the peripheral wind speed distribution, we analysis the wind-induced response of catenaries with the method of theoretical analysis, which provide the evidence to the choosing of the form of an elastic suspension or simple suspension and determine the direction of the catenary design[3].

\section{CALCUlation MODEL}

\section{A. Calculation Model Overview}

This paper selects a straight-shaped straight section on the suspension, and deemed fully compensated catenary, in the analysis, the tensions of load-bearing wire and contact wire catenary contact lines are constant.. The model contains $4 \times 50 \mathrm{~m}$ elastic catenary (German) and simple catenary (Japan) [4]. Droppers arrangement is shown in Fig. 1 and Fig.2.

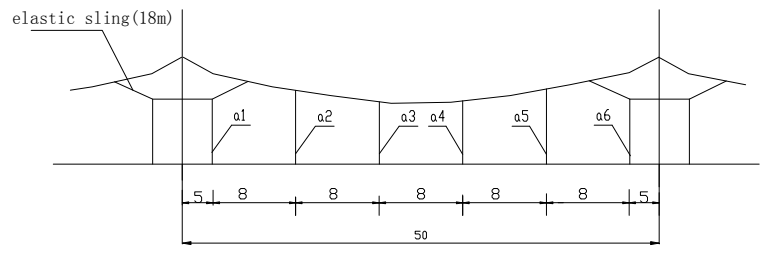

Figure 1. Bomb droppers chain suspension arrangement 


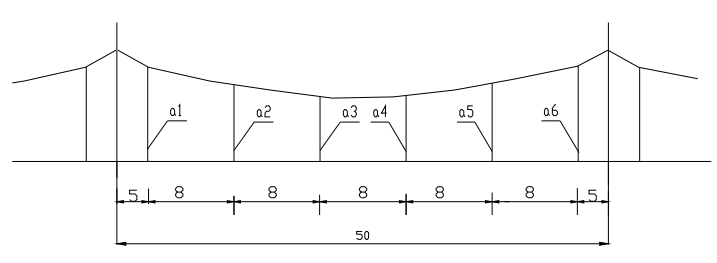

Figure 2. Simple chain suspension arrangement dropper

Controlling parameter structure is the lateral limits of $3.15 \mathrm{~m}$; staggers $0.25 \mathrm{~m}$, structural height $1.6 \mathrm{~m}$, simple chain (Japanese) for the elastic chain (Ashkenazi) 0.95m. The main design parameters of the structure as shown in Table I .

TABLE I. MAIN MATERIAL DESIGN PARAMETERS

\begin{tabular}{cccc}
\hline Name & $\begin{array}{c}\text { Sectional } \\
\text { area }\left(\mathbf{m m}^{\mathbf{2}}\right)\end{array}$ & $\begin{array}{c}\text { Design of } \\
\text { tension }(\mathbf{k N})\end{array}$ & $\begin{array}{c}\text { The outer } \\
\text { diameter }(\mathbf{m m})\end{array}$ \\
\hline Bearing line & 116.99 & 23 & 14 \\
Contact wire & 151 & 31.5 & 14.4 \\
Droppers & 9.62 & Weight & 4.5 \\
Elastic sling & 34.36 & 3.5 & 7.5 \\
\hline
\end{tabular}

By large general-purpose finite element software ANSYS, the establishment, including columns, wrist suspension system and the contact system three-dimensional finite element model of the span $50 \mathrm{~m}$ across four bomb chain, finite element model simple chain and elastic chain in Fig. 3 and Fig.4, the figure for the roadbed lateral $\mathrm{X}$ axis, $\mathrm{Z}$ axis is the longitudinal embankment, $\mathrm{Y}$ axis is vertical.

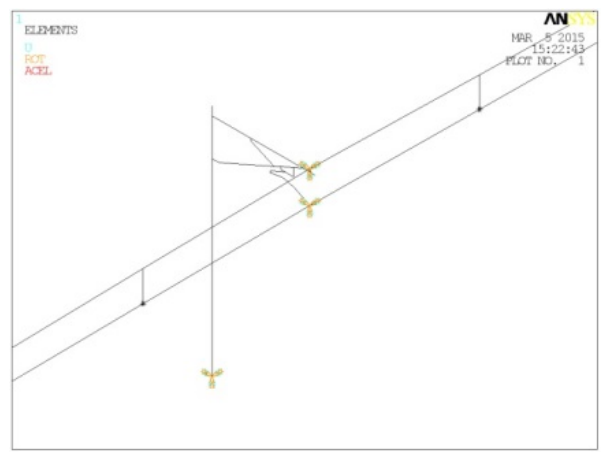

Figure 3. Japanese model simple chain across the map and reverse 4 location map

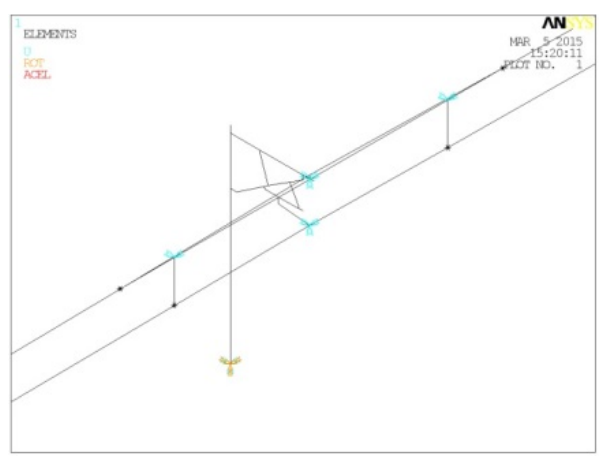

Figure 4. German bomb chain model in 4 Cross and the pros and cons location map

\section{B. Catenary Flexible Computing and Verification}

The results herein catenary elasticity finite model calculation results with existing literature and empirical comparison; verify the correctness of the finite element model by the contrast.

a. The elastic calculation results of wind-induced vibration model

The results herein catenary elasticity finite model calculation results with existing literature and empirical comparison; verify the correctness of the finite element model by the contrast.

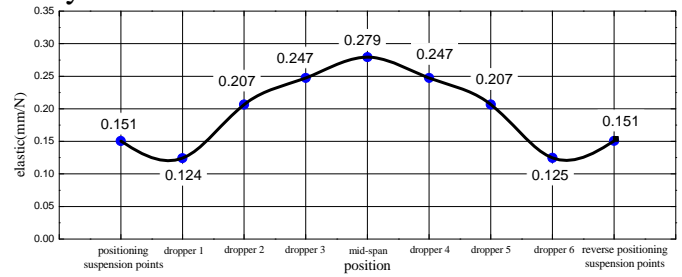

Figure 5. Simple chain elasticity in the span of variation diagram

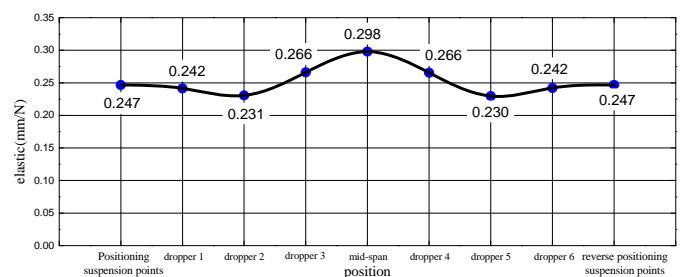

Figure 6. Bomb chain elasticity in the span of variation diagram

b. Elastic literature and empirical formula calculation

According to"high-speed electrified railway catenary" (Yu Wan-ju)[5]: Germany Re250 and Re330 type catenary type elastic computing, its simple chain span at the center of the elastic suspension is calculated as:

$$
\eta_{\max }=\frac{l}{4 \times\left(T_{j}+T_{c}\right)}
$$

Its elastic chain elastic suspension span is calculated at the center of:

$$
\eta_{\max }=\frac{l}{3.5 \times\left(T_{j}+T_{c}\right)}
$$

Where $l$-span length $(\mathrm{m}) ; T_{j}$-catenary tension $(\mathrm{kN})$; $T_{c}$-contact wire tension $(\mathrm{kN})$.

Only achieve $30 \%$ of the value of cross-catenary If the suspension point is not elastic sling hanging point elastic: according to "electrified railway catenary"[6](KieBling, Railway Electrification Bureau Group Co. translation) $50 \%$, but with elastic sling elastic catenary point may be about to $90 \%$ span value. Catenary elasticities and empirical formula results and literature values of model calculations herein limited compared in Table II .

TABLE II. CONTACTS GATEWAy Key PARTS OF THE ElAstic COMPUTE CONTRAST (ELASTIC UNIT: mm / N)

\begin{tabular}{ccccc}
\hline Project & \multicolumn{2}{c}{ Jane chain } & \multicolumn{2}{c}{ Bomb chain } \\
\hline Location & Span & Hanging point & Span & Hanging point \\
\hline Empirical formula & 0.230 & $0.069 ~ 0.115$ & 0.262 & 0.236 \\
FEM & 0.280 & 0.151 & 0.298 & 0.247 \\
Reference [7] & 0.333 & 0.123 & 0.305 & 0.198 \\
\hline
\end{tabular}

c. Flexible comparison results

This paper established a simple chain, wind-induced vibration model bomb chain force balance established by the locator model, the intent was more realistic catenary wind-induced vibration simulation.

Wind-induced vibration finite model and finite 
element model of the existing literature comparing the resulting simplified chain, same bullet chain variation trend is resilient[8]; and empirical and comparative literature, contacts the gateway key parts of elastic computing results are basically the same as in Table II .

The results from the perspective of flexibility, this model of wind-induced vibration limited scientific.

\section{CALCULATION OF STATIC WIND}

\section{A. Static Load}

According to aerodynamic theory, the role of the contact line of force size[9]: $\quad F_{D}=\frac{1}{2} \rho U^{2} D L C_{D}$

Where: $\rho$ is the air density, $D$ is the diameter of catenary, droppers and contact line, $L$ is the length, $C_{D}$ of the contact line, drag coefficient catenary and hanging string. $U$ as in catenary height wind speed can be calculated by the following formula, namely: $U=K \times U_{10}\left(\frac{H}{10}\right)^{\alpha}$ (4)

Where $U_{10}$ is the wind speed from the surface 10 meters at a height, $H$ for the catenary height of each point from the ground. It is the surface roughness index, where take 0.16 . $K$ for the installation of a wind screen (wall) after catenary height wind speed reduction factor. When there is no windshield $\mathrm{K}=1.0$.

According to the wind screen hole test results, catenary wind speed amplification factor of 1.12, the wind attack angle $16.8^{\circ}$, the drag coefficient wind axis is 0.8 . According to the results of the wind screen hole test, the wind speed reduction factor of the contact line of 0.76 , angle of attack of $13.7^{\circ}$, the drag coefficient air shaft 0.77 . In the calculation process for security purposes, the contact line of wind speed reduction factor of 1.0.

\section{B. Calculation of Static Wind}

Fig.7 and Fig.8 horizontal displacement means the displacement direction perpendicular line, measured from the centerline of the line, the right level of positive vertical displacement of vertical displacement, measured from the contact line design position, upright is positive. Calculations show that, compared with the simple elastic chain chain, average wind partial elastic chain chain than simply big.
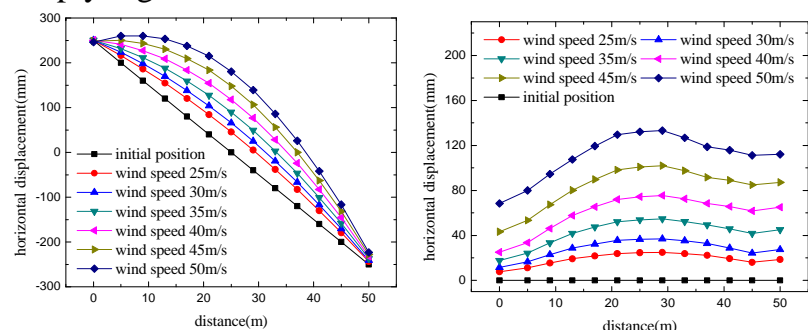

Figure 7. Simple horizontal and vertical chain contact line deviatio
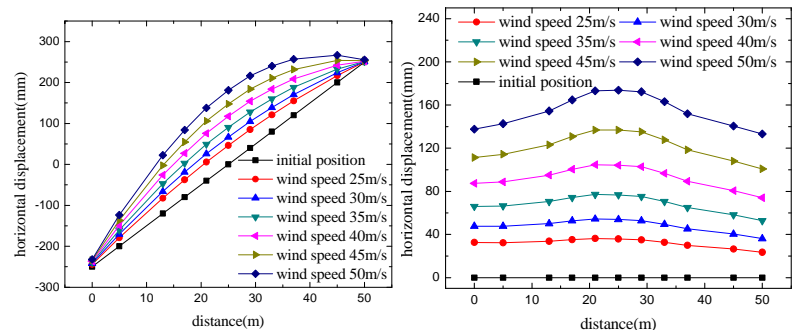

Figure 8. Bomb chain contact line horizontal and vertical deviation

Description: horizontal deviation refers to the horizontal distance from the center line deviation to the right level is positive. Vertical lift means the contact line design deviates from the vertical height of the distance in the vertical direction is positive. At a distance of $0 \mathrm{~m}$ positive locator at the distance $\pm 50 \mathrm{~m}$ at anti locator place[10].

\section{IV.FLUCTUATING WIND DYNAMIC ANALYSIS}

\section{A. Overview of The Three-Dimensional Numerical Simulation of The Wind Spectrum}

Natural wind in time and space are random, structural wind analysis generally be regarded as approximate dimensional multivariate each state through a stationary Gaussian process. This paper wind spectrum simulated using spectrum solution. Spectrum solution is characterized by a simple algorithm, theoretical perfect consistency of each state Gaussian their samples, mean and correlation function, mean and correlation function characteristics are obtained through mathematical proofs, simulation results are more reliable.

Vertical wind profile line selection Simiu wind speed

$$
\text { spectrum: } \quad S_{\mathrm{u}}(\omega)=\frac{100 Z u_{*}^{2}}{\pi U(Z)\{1+25 \omega \mathrm{Z} /[\pi U(Z)]\}^{5 / 3}}
$$

Vertical wind profile selection Lumlely-Panofsky wind speed spectrum:

$$
S_{\mathrm{v}}(\omega)=\frac{3 Z u_{*}^{2}}{\pi U(Z)\{1+2 \omega Z /[\pi U(Z)]\}^{2}}
$$

Using WAWS for selected stationary Gauss random process wind spectrum simulation of n-dimensional wind field spectrum.

\section{B. Catenary Fluctuating Wind Power History Analysis}

The dynamic analysis is based on the previous stage linear analysis performed[11], the simulation time step $1 / 48$ s, modal damping ratio of $0.5 \%$, a total of 9999 times the full method transient analysis. Partial results shown in Fig. 9 to Fig. 10.
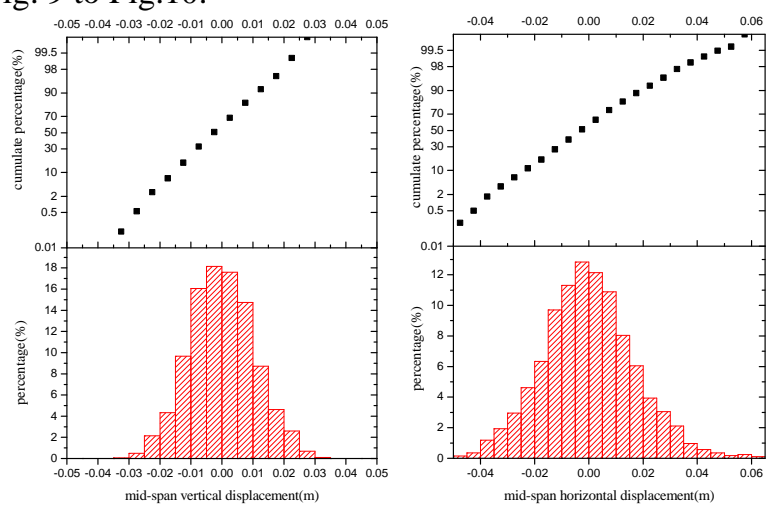

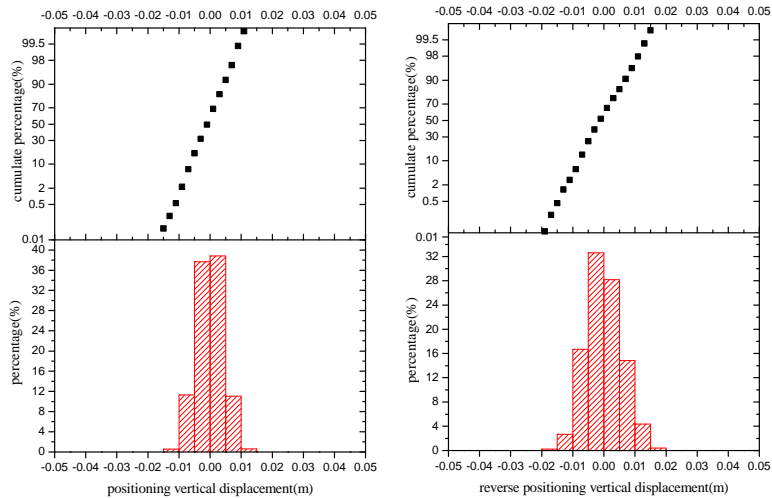

Figure 9. Simple chain of wind-induced vibration displacement distribution
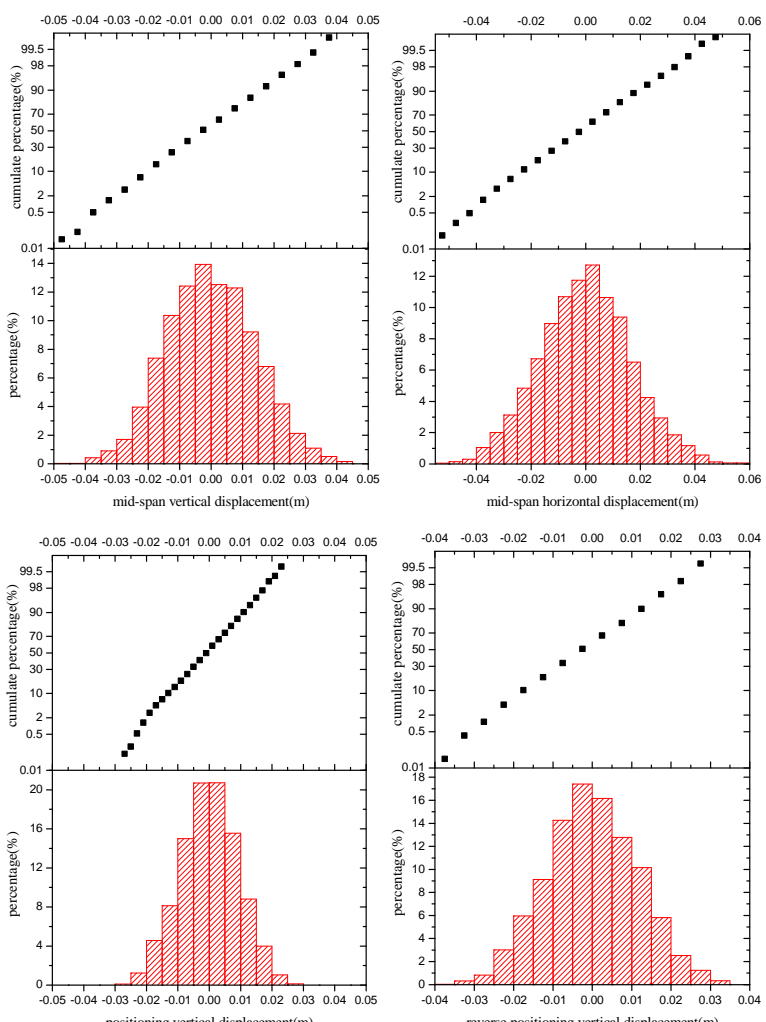

Figure 10. Bomb chain wind-induced vibration displacement distribution
TABLE III. SIMPLE CHAIN, PLAYING ACROSS THE LINE OF CONTACT CHAIN MAXIMUM VIBRATION DISPLACEMENT SUMMARY

\begin{tabular}{ccc}
\hline Project & $\begin{array}{c}\text { Jane } \\
\text { chain }\end{array}$ & $\begin{array}{c}\text { Bomb } \\
\text { chain }\end{array}$ \\
\hline $\begin{array}{c}\text { Cross the vertical displacement root of } \\
\text { variance (m) }\end{array}$ & 0.00836 & 0.01129 \\
$\begin{array}{c}\text { Span horizontal displacement root of } \\
\text { variance (m) }\end{array}$ & 0.01322 & 0.01313 \\
$\begin{array}{c}\text { Positive locator vertical displacement at } \\
\text { the root of the variance (m) }\end{array}$ & 0.00455 & 0.00924 \\
$\begin{array}{c}\text { Anti locator at the root of the variance of } \\
\text { the vertical displacement (m) }\end{array}$ & 0.00331 & 0.00734 \\
$\begin{array}{c}\text { Cross the maximum vertical displacement } \\
\text { (m) }\end{array}$ & -0.03368 & -0.04609 \\
$\begin{array}{c}\text { Cross the maximum horizontal } \\
\text { displacement (m) }\end{array}$ & 0.06275 & 0.05905 \\
$\begin{array}{c}\text { Vertical displacement at the maximum } \\
\text { positive Locator (m) }\end{array}$ & -0.01838 & -0.03630 \\
$\begin{array}{c}\text { Vertical position at the maximum anti } \\
\text { Locator (m) }\end{array}$ & -0.01487 & -0.02716 \\
\hline$\quad$ V. CONCLUSION & & \\
\hline
\end{tabular}

1. As can be seen from the list of data, consider column wrist and other support systems flexibility and elasticity of this support does not consider the results of the static wind analysis system has little effect[12].

2. by a simple chain, bomb chain lateral deviation can be seen, when the wind speed between $25 \mathrm{~m} / \mathrm{s} \sim 40 \mathrm{~m} / \mathrm{s}$ maximum deviation of the position is still at the front and back setter, when the wind speed at $50 \mathrm{~m} / \mathrm{s} \sim 65 \mathrm{~m} / \mathrm{s}$ of time position of maximum deviation from the anti-locator shift at the mid-span, the wind speed is higher, the maximum deviation from the position closer to the span.

3. by a simple chain, bomb chain vertical uplift can be seen, the maximum lifting distance in cross or across the neighborhood. Uplift uplifting than simple elastic chain chain more even more.

4. The maximum displacement summary charts and contact line can be seen from the time history, on power issues, structural height and structure of highly elastic chain chain $1.6 \mathrm{~m} 0.95 \mathrm{~m}$ Jane, in the case of other design parameters consistent, contact line vibration displacement difference is small.

\section{REFERENCES}

[1] Yu. A. Mushenkov. The dynamic stability of physically nonlinear catenary arches[J]. Soviet Applied Mechanics, 1970,31:.

[2] Tong-Jin Park,Byung-Jin Kim,Young-Yong Wang,Chang-Soo Han. A catenary system analysis for studying the dynamic characteristics of a high speed rail pantograph[J]. KSME International Journal,2002,164:

[3] Weihua Zhang,Ning Zhou,Ruiping Li,Guiming Mei,Dongli Song. Pantograph and catenary system with double pantographs for high-speed trains at $350 \mathrm{~km} / \mathrm{h}$ or higher[J]. Journal of Modern Transportation,2011,191:

[4] S. Avila-Sanchez,J. Meseguer,O. Lopez-Garcia. Turbulence intensity on catenary contact wires due to parapets placed on a double track bridge[J]. Journal of Wind Engineering \& Industrial Aerodynamics,2010,9810:.

[5] Yu Wanju,high-speed electrified railway catenary[M]. Southwest Jiaotong University press, 2003.

[6] KieBling, electrified railway catenary [M]. China Electric Power Press, 2003.

[7] Hao Fangtao, The calculation of elasticity and its unevenness of overhead contact system based on finite element [D]. Southwest Jiaotong University, 2010. 
[8] Wu Jialan, The study of wind-induced response for catenary system of high-speed [D]. Southwest Jiaotong University, 2008.

[9] Peng Wei,Sun Bingnan,Tang Jinchun. A catenary element for the analysis of cable structures[J]. Applied Mathematics and Mechanics . 1999 (5).

[10] Klaus-Jurgen Bathe. Finite Element Procedures[M]. Prentice-Hall, Englewood Cliffs, New Jersey,1996.
[11] Yang,You-fa;Bai,Wen-Xuan;Gao,Jian-ren. Application of catenary solution in numerical analysis of stayed cables[J].Source:Chongqing Jianzhu Daxue Xue bao of Chongqing Jianzhu University,V29,n6,p31-34,December 2007.

[12] G.Augusti,et. On the time domain analysis of wind response of structures[J]. Journal of Wind Engineering and Industrial Aerodynamics, Vol.23,1996. 